\title{
Identification of neovasculature using nestin in colorectal cancer
}

\author{
NOBUHISA TERANISHI ${ }^{1,2}$, ZENYA NAITO $^{2}$, TOSHIYUKI ISHIWATA ${ }^{2}$, NORITAKE TANAKA ${ }^{3}$, \\ KIYONORI FURUKAWA ${ }^{1}$, TOMOKO SEYA ${ }^{3}$, SEIICHI SHINJI ${ }^{1,2}$ and TAKASHI TAJIRI ${ }^{1}$ \\ Departments of ${ }^{1}$ Surgery for Organ Function and Biological Regulation (Department of Surgery), \\ and ${ }^{2}$ Integrative Pathology (Department of Pathology II), Graduate School of Medicine, \\ Nippon Medical School, 1-1-5 Sendagi, Bunkyo-ku, Tokyo 113-8602; ${ }^{3}$ Department of Surgery, \\ Chiba Hokusoh Hospital, Nippon Medical School, 1715 Kamagari, Inba, Chiba 270-1694, Japan
}

Received October 5, 2006; Accepted December 3, 2006

\begin{abstract}
CD34 is commonly used as an endothelial cell marker of tumor vessels. However, this marker detects not only newly formed, but also pre-existing large blood vessels. Nestin, a class VI intermediate filament protein, has recently received attention as a marker for detecting newly formed endothelial cells. In this study, whether nestin is a novel angiogenesis marker in colorectal cancer was examined. HCT-15, a human colon cancer cell line, was subcutaneously implanted into the dorsum of nude mice. After the tumor grew, the mice were perfused with fluorescent beads (Fluospheres). Then, the tumor tissues were used for immunofluorescence staining using nestin and the CD34 antibody. Immunohistochemistry was performed with nestin and CD34 on 101 human colorectal cancer tissue samples. Proliferating endothelial cells were detected immunohistochemically by a proliferating cell nuclear antigen (PCNA) antibody. Clinicopathological factors and prognosis were compared between two groups: that with a microvessel density (MVD) higher than the median MVD and that with MVD lower than the median MVD, as detected by nestin and CD34 labellings. Nestin was localized in endothelial cells in small blood vessels (median, $9.06 \mu \mathrm{m}$ ), whereas CD34 was localized in large blood vessels (median, $9.67 \mu \mathrm{m}$ ) in nude mice. The diameter of nestin-positive vessels was smaller than that of CD34-positive vessels in human colorectal cancer. The number ratio of PCNA-positive cells to nestin-positive vascular endothelial cells was higher than that of PCNA-positive to CD34-positive cells ( $\mathrm{p}=0.002$ ). There were no correlations between nestin-positive blood vessels and clinicopathological factors, but the prognosis was worse in the highly nestin-positive MVD group ( $\mathrm{p}=0.071)$. Nestin
\end{abstract}

Correspondence to: Dr Zenya Naito, Department of Integrative Pathology (Department of Pathology II), Graduate School of Medicine, Nippon Medical School, 1-1-5 Sendagi, Bunkyo-ku, Tokyo 113-8602, Japan

E-mail: naito@nms.ac.jp

Key words: nestin, endothelial cell, colorectal cancer, immunohistochemistry, Fluospheres is considered a novel angiogenesis marker of proliferating endothelial cells in colorectal cancer tissue.

\section{Introduction}

Tumor angiogenesis is an important factor in the proliferation and metastasis of human neoplasms. The degree of tumor angiogenesis is associated with clinical outcome, because angiogenic properties correlate with tumor aggressiveness $(1,2)$. Above all, tumor angiogenesis is thought to be essential in tumor metastasis to distant organs (3). A possible explanation of this metastatic mechanism is that an increase in the number of tumor vessels increases the chances for tumor cells to enter circulation, and newly formed vessels or capillaries have leaky and weak basement membranes, to which tumor cells can penetrate more easily than those of mature vessels (4). Thus, patients with highly vascularized tumors are significantly more likely to die than those with less vascularized tumors. Angiogenesis in malignant neoplasms, as measured in terms of microvessel density (MVD), has been reported to correlate with clinicopathological factors or survival in breast carcinoma, ovarian carcinoma, malignant melanoma, non-small-cell lung carcinoma, prostatic carcinoma, esophageal carcinoma, gastric cancer and colorectal cancer (1,2,5-10).

CD34, CD31 and the factor VIII-related antigen are commonly used as endothelial cell markers of tumor vessels, and MVD is determined by blood vessels stained with these endothelial markers (11-13). However, these markers identify not only newly formed small blood vessels, but also preexisting large blood vessels (14).

Nestin is a class VI intermediate filament protein originally found in neuroepithelial stem cells and neural cells (15). Nestin forms intermediate filament bundles with vimentin by copolymerization in neuroepithelial cells (16). Nestin mRNA is expressed at a high level in the cerebrum of developing rat embryos on embryonic day 15 , the level decreases toward postnatal day 12, and disappears from postnatal day 18 to the adult stage (15). High levels of nestin expression are detected outside the nervous tissue in the oligodendroglial lineage, Sertoli cells, hair follicle cells, stellate cells, pericytes, islets and odontoblasts (17-23). Nestin is also present in skeletal muscle progenitors, cardiac muscle progenitors of reproducing organizations, infarcted myocardium, and neoplasms (24-27). 
Recently, nestin expression in endothelial cells accompanying the process of angiogenesis has been reported (28). Nestin is strongly expressed in proliferating endothelial cells in acute pancreatitis (29). Furthermore, nestin was reported to be a marker of proliferating endothelial cells in brain tumor tissues (27). In gastric adenocarcinoma, MVD determined by nestin-positive blood vessels correlated with survival better than MVD determined by CD34-positive blood vessels (30).

In this study, we examined the effectiveness of nestin as a marker of angiogenesis in colorectal cancer. It is difficult to identify small blood vessels by common histological techniques. Thus, we identified tumor blood vessels using fluorescent carboxylate-modified polystyrene beads (Fluospheres) in nude mice (31). Fluospheres, which are smaller than blood corpuscles, can diffuse into small blood vessels $(32,33)$. Fluospheres of $0.2 \mu \mathrm{m}$ in diameter behave similarly to fluid and completely fill vessels; however, they do not leak from CD34-positive vessels and remain localized in histological sections (34). After the identification of all blood vessels using Fluospheres, the diameters of nestin-positive and CD34positive vessels were compared in subcutaneous colorectal cancer tumors formed in nude mice.

Immunohistochemistry was also performed on colorectal cancer tissue from colorectal cancers patients with nestin and CD34. Moreover, we determined the ratio of proliferating cell nuclear antigen (PCNA)-positive to nestin-positive or CD34-positive endothelial cells in the tumor. The predictive value of angiogenesis determined by CD34 and that determined by nestin in the same group of patients were compared to evaluate whether nestin is a more effective marker of angiogenesis in colorectal cancer.

\section{Materials and methods}

Materials. The following materials were purchased: pGEM-T vectors from Promega Biotech. (Madison, WI, USA); a digoxigenin (DIG) nucleic acid detection kit and a DIG RNA labeling kit from Roche Diagnostics (Mannheim, Germany); yeast tRNA from Gibco BRL (Gaithersburg, MD, USA); Tween-20, glycine and formamide from Wako Pure Chemical Industries, Ltd. (Osaka, Japan); Isogen from Nippon Gene (Tokyo, Japan); a Takara RNA PCR kit (AMV) Ver. 3.0 from Takara Biotech. (Tokyo, Japan); a Histofine Simple Stain PO (M) or (G) Max kit and mouse monoclonal anti-human CD34 antibody from Nichirei Biosciences Inc. (Tokyo, Japan); mouse monoclonal anti-human nestin antibody from R\&D Systems, Inc. (Minneapolis, MN, USA); mouse monoclonal anti-human PCNA antibody from Dako Cytomation (Kyoto, Japan); goat polyclonal anti-mouse nestin antibody from Santa Cruz Biotech. (Santa Cruz, CA, USA); rat monoclonal anti-mouse CD34 antibody from BD Biosciences Pharmingen (San Jose, CA, USA); superfrosted slides with a MAS coat from Matsunami Glass Ind., Ltd. (Osaka, Japan); a malinol mounting medium from Mutoh Chemical Co. (Tokyo, Japan); antibiotics and antimycotics from Invitrogen Co. (Carlsbad, CA, USA); Fluospheres of $0.2 \mu \mathrm{m}$ in diameter from Molecular Probes (Leiden, The Netherlands); male BALB/C nu/nu mice from Clea Japan (Tokyo, Japan); sodium pentobarbital from Dainippon Sumitomo Pharma Co. (Osaka, Japan); nitroglycerin from Nippon Kayaku, Co. (Tokyo, Japan); FITC-conjugated anti-goat IgG secondary antibody from Vector Laboratories, Inc. (Burlingame, CA, USA); OCT compound from Sakura Finetechnical Co. (Tokyo, Japan); and Texas Red-conjugated anti-rat IgG secondary antibody from Abcam (Cambridge, UK). All other chemicals and reagents were purchased from Sigma Chemical Co. (St. Louis, MO, USA)

Colorectal cancer cell line. HCT-15, a colorectal cancer cell line, was obtained from the Cell Resource Center for Biomedical Research Institute of Development, Aging and Cancer Tohoku University (Sendai, Japan). The cells were grown in RPMI-1640 medium containing 10\% heat-inactivated fetal bovine serum (FBS), $200 \mathrm{U} / \mathrm{ml}$ penicillin and $200 \mu \mathrm{g} / \mathrm{ml}$ kanamycin at $37^{\circ} \mathrm{C}$ under a humidified $5 \% \mathrm{CO}_{2}$ atmosphere.

Evaluation of blood vessels in nude mice using Fluospheres. HCT-15 colorectal cancer cells $\left(5 \times 10^{6}\right.$ cells/mouse $)$ were implanted subcutaneously into the dorsum of nude mice (10 animals), and newly formed blood vessels in the tumor were counted. After implantation, tumor size was measured using calipers (35). When the tumor reached $3 \mathrm{~cm}$ in diameter, the mice were used in this study. The injection of Fluospheres into nude mice was performed according to a previous report (34). Briefly, the mice were anesthetized with an intraperitoneal injection of Nembutal. Nitroglycerin was included in the Nembutal at $50 \mu \mathrm{g} / \mathrm{ml}$ to induce maximal vasodilation of the peripheral vasculature. Then, the chest was opened by midline sternotomy. The left ventricle was identified and the ventricular cavity was entered through the apex with a 26-gauge needle. The right ventricle was identified and an incision was made on the free wall to exsanguinate the animal and to allow the excess perfusate to exit the vascular space. The animal was perfused with approximately $10 \mathrm{ml}$ of phosphatebuffered saline (PBS) with Fluospheres for 1 min. After perfusion was completed, the tumor was excised with the surrounding tissue and mounted in the OCT compound. Serial tissue sections of $10-\mu \mathrm{m}$ thickness were prepared using a cryostat. This study was approved by the Animal Ethics Committee of Nippon Medical School.

Immunofluorescence. The tissue sections were immersed in PBS and then incubated with the appropriate antibody (1:500 dilution for the anti-mouse nestin antibody and 1:200 dilution for the anti-mouse CD34 antibody) in PBS containing 1\% bovine serum albumin (BSA) for $16 \mathrm{~h}$ at $4^{\circ} \mathrm{C}$. For nestin, the sections were incubated with the FITC-conjugated anti-goat secondary antibody in PBS containing 1\% BSA and 10\% mouse serum for $1 \mathrm{~h}$ at room temperature (RT). For CD34, the sections were incubated with the biotin-conjugated antirat secondary antibody for $1 \mathrm{~h}$ at RT. Then, the sections were incubated with Texas Red-conjugated streptavidin for $1 \mathrm{~h}$ at RT. The tumor tissues of the mice were observed under a fluorescence microscope (Nikon Corporation, Tokyo, Japan). The diameters of nestin-positive and CD34-positive blood vessels in which the Fluospheres were injected were calculated in the same fields. The median microvessel count was used for statistical analyses.

Human colorectal cancer tissues. One hundred and one colorectal cancer patients who participated in this study were 
Table I. Clinicopathological features of colorectal cancer patients.

Variable

\section{Sex}

Male

Female

Mean age \pm SD (range)

$65.45 \pm 10.93(27-91)$

Histology

Well/moderate

Poor/mucinous

Location

Colon

Rectum

Depth of tumor invasion

m-sm

mp-si

p-stage

0 -II

III-IV

Lymphatic invasion

Positive

Negative

Vascular invasion

Positive

Negative

Lymph node metastasis

Positive

Negative

from those receiving treatment at Nippon Medical School Hospital (Bunkyo-ku, Tokyo, Japan) in 1999. The clinicopathological features of the patients are summarized in Table I. Formalin-fixed and paraffin-embedded specimens were prepared for immunohistochemistry and in situ hybridization. This study was carried out in accordance with the principles embodied in the Declaration of Helsinki, 1975, and informed consent for the usage of colorectal tissues was obtained from each patient.

Immunohistochemistry. The paraffin-embedded serial tissue sections $(3.5 \mu \mathrm{m})$ were subjected to immunostaining for nestin, CD34 and PCNA using the Histofine Simple Stain PO (M) or (G) Max kit. After deparaffinization, endogenous peroxidase activity was blocked by incubation with $0.3 \%$ hydrogen peroxide in methanol for $30 \mathrm{~min}$. For PCNA immunostaining, sections were pretreated in an autoclave at $121^{\circ} \mathrm{C}$ for $15 \mathrm{~min}$ in $10 \mathrm{mM}$ citrate buffer $(\mathrm{pH} 6.0)$. Then the tissue sections were incubated with the appropriate antibody (1:100 dilution for the anti-human nestin antibody, 1:150 dilution for the

anti-human CD34 antibody and 1:200 dilution for the antiPCNA antibody) in PBS containing $1 \%$ BSA for $16 \mathrm{~h}$ at $4^{\circ} \mathrm{C}$. Bound antibodies were detected with the Histofine Simple Stain PO (M) or (G) Max reagents using diaminobenzidine tetrahydrochloride (DAB) as the substrate, and the sections were counterstained with Mayer's hematoxylin. Negative control experiments were performed by omitting the primary antibodies. The diameter of the blood vessels was calculated in the colorectal cancers as previously described in nude mouse tissues. Blood vessels forming lumens were selected and each image was captured using an Olympus DP12 Digital Camera system (Olympus Optical, Tokyo, Japan) attached to an Olympus AX80 microscope at x200 magnification. Then, nestin- and PCNA-positive endothelial cells or CD34- and PCNA-positive endothelial cells were counted.

Probe preparation and in situ hybridization. A 235-bp BamHIEcoRI cDNA fragment, corresponding to nucleotides 10191253 of the human nestin cDNA sequence, was subcloned into the pGEM-T vector and the result was confirmed by sequencing. Probes were labeled with digoxigenin (DIG)-UTP using the DIG RNA-labeling kit. In situ hybridization was carried out as previously reported $(29,36)$. Tissue sections were deparaffinized and incubated at RT for $20 \mathrm{~min}$ with $0.2 \mathrm{M}$ $\mathrm{HCl}$ and then at $37^{\circ} \mathrm{C}$ for $15 \mathrm{~min}$ with $100 \mu \mathrm{g} / \mathrm{ml}$ proteinase $\mathrm{K}$. The sections were postfixed for $5 \mathrm{~min}$ in PBS containing $4 \%$ paraformaldehyde (PFA), and incubated twice for $15 \mathrm{~min}$ each in PBS containing $2 \mathrm{mg} / \mathrm{ml}$ glycine and once in $2 \mathrm{X}$ standard saline citrate (SSC) containing $50 \%$ formamide for $1 \mathrm{~h}$ before the initiation of the hybridization reaction. Hybridization was carried out in a moist chamber for $16 \mathrm{~h}$ at $42^{\circ} \mathrm{C}$. The sections were then washed sequentially with $2 \mathrm{X}$ SSC for $20 \mathrm{~min}$ at $42^{\circ} \mathrm{C}$, and with $0.2 \mathrm{X} \mathrm{SSC}$ for $20 \mathrm{~min}$ at $42^{\circ} \mathrm{C}$. For immunological detection, the DIG nucleic acid detection kit was used. The sections were washed briefly with buffer 1 (100 mM Tris $\mathrm{HCl}$ and $150 \mathrm{mM} \mathrm{NaCl}, \mathrm{pH} 7.5)$, incubated with $1 \%(\mathrm{w} / \mathrm{v})$ blocking reagents in buffer 1 for $1 \mathrm{~h}$ at RT, and thereafter incubated with alkaline phosphataseconjugated polyclonal sheep anti-DIG Fab fragment containing $0.2 \%$ Tween-20 at 1:2000 dilution for $1 \mathrm{~h}$ at RT. The sections were then washed twice for $15 \mathrm{~min}$ at RT with buffer 1 containing $0.2 \%$ Tween-20, equilibrated in buffer $3(100 \mathrm{mM}$ Tris $\mathrm{HCl}, 100 \mathrm{mM} \mathrm{NaCl}$ and $50 \mathrm{mM} \mathrm{MgCl}_{2}, \mathrm{pH} 9.5$ ) for $2 \mathrm{~min}$, and incubated in the staining solution containing nitroblue tetrazolium and X-phosphate in a dark box for 2-3 h. After the reaction was stopped with a Tris-EDTA acid buffer $(10 \mathrm{mM}$ Tris- $\mathrm{HCl}$ and $1 \mathrm{mM}$ EDTA, $\mathrm{pH} 8.0$ ), the sections were mounted in an aqueous mounting medium.

Microvessel counting. MVD was assessed in accordance with an international consensus report (37). Briefly, slides immunostained with the anti-human nestin antibody were scanned at a x100 magnification to identify the areas with the highest number of vessels. Then, images of the blood vessels stained with anti-human nestin or anti-human CD34 antibodies were captured using an Olympus DP12 Digital Camera system attached to an Olympus AX80 microscope at a x200 magnification in the same areas using serial tissue sections. Each x200 magnification area was $0.64 \mathrm{~mm}^{2}$. Counts were determined in five separate fields. All stained endothelial 

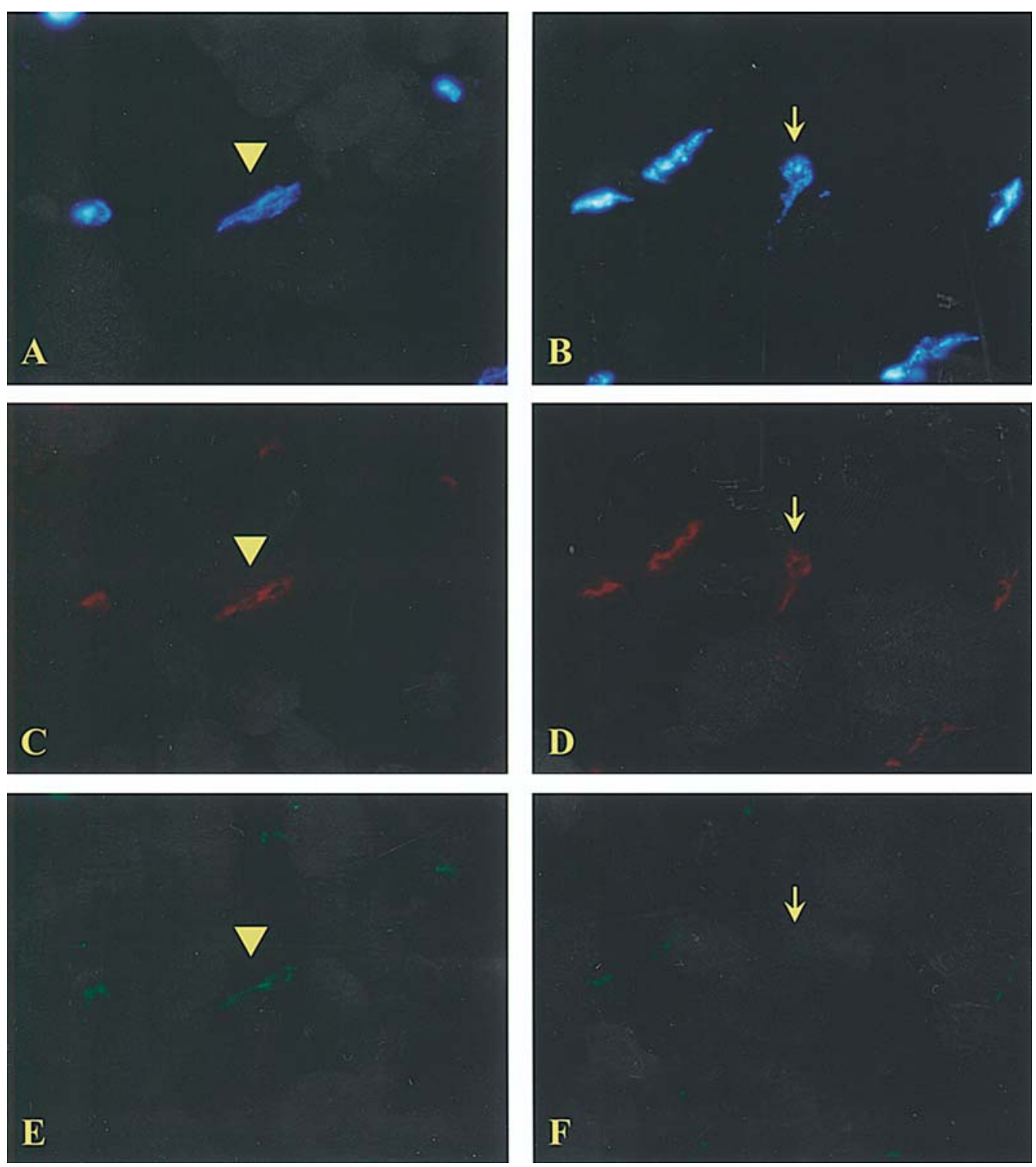

Figure 1. Fluospheres, CD34 and nestin in subcutaneous tumor in nude mice. Fluospheres were detected in blood vessels of various sizes (A and B). CD34 and nestin were colocalized in vascular endothelial cells (C and E, arrowheads). In some vascular endothelial cells, CD34 was detected, but not nestin (D and F, arrows). Fluospheres (A and B), CD34 (C and D), and nestin (E and F). Immunofluorescence original magnification: A-F, x400.

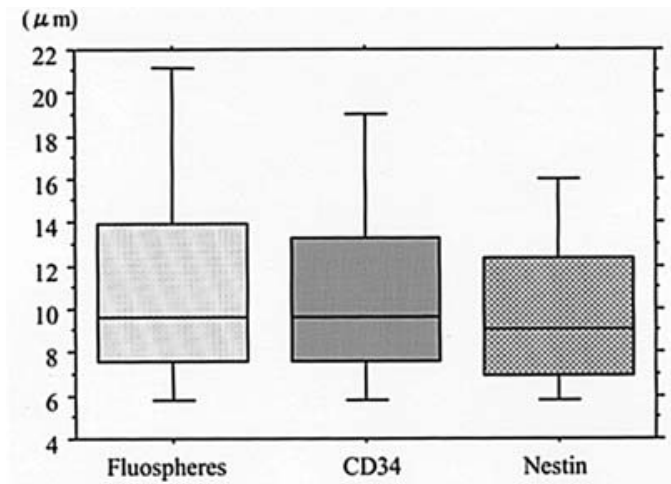

Figure 2. Diameters of CD34- and nestin-positive vascular endothelial cells in nude mice. Fluospheres were detected in blood vessels with a median lumen diameter of $9.97 \mu \mathrm{m}$ (mean, 12.42 \pm 9.20 ; range, 2.72-75.83). CD34 was immunostained in blood vessels with a median diameter of $9.67 \mu \mathrm{m}$

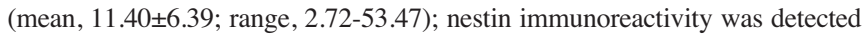
in endothelial cells of smaller blood vessels with a median diameter of $9.06 \mu \mathrm{m}$ (mean, 10.25 \pm 4.49 ; range, 2.72-28.70) $(\mathrm{p}=0.073)$. cells or cell clusters were counted as one microvessel and the presence of lumen was not required. The median microvessel count was used for analysis. Two investigators separately counted MVD in the same specimens without any clinical information. No difference was found between the two data sets $\left(\mathrm{r}^{2}=0.838 ; \mathrm{p}<0.0001\right)$.

Statistical analyses. To analyze the correlations of clinicopathological factors with nestin-positive or CD34-positive endothelial cells, or the expression of PCNA, the chi-square test was used. The Mann-Whitney U-test was used to compare the diameters of nestin-positive and CD34-positive blood vessels. The unpaired t-test was used to analyze the correlation between clinicopathological features and two groups: that with MVD higher than the median MVD and that with MVD lower than the median MVD. Disease-free survival curves were computed according to the Kaplan-Meier method; differences in disease-free survival were computed using the log-rank test. 

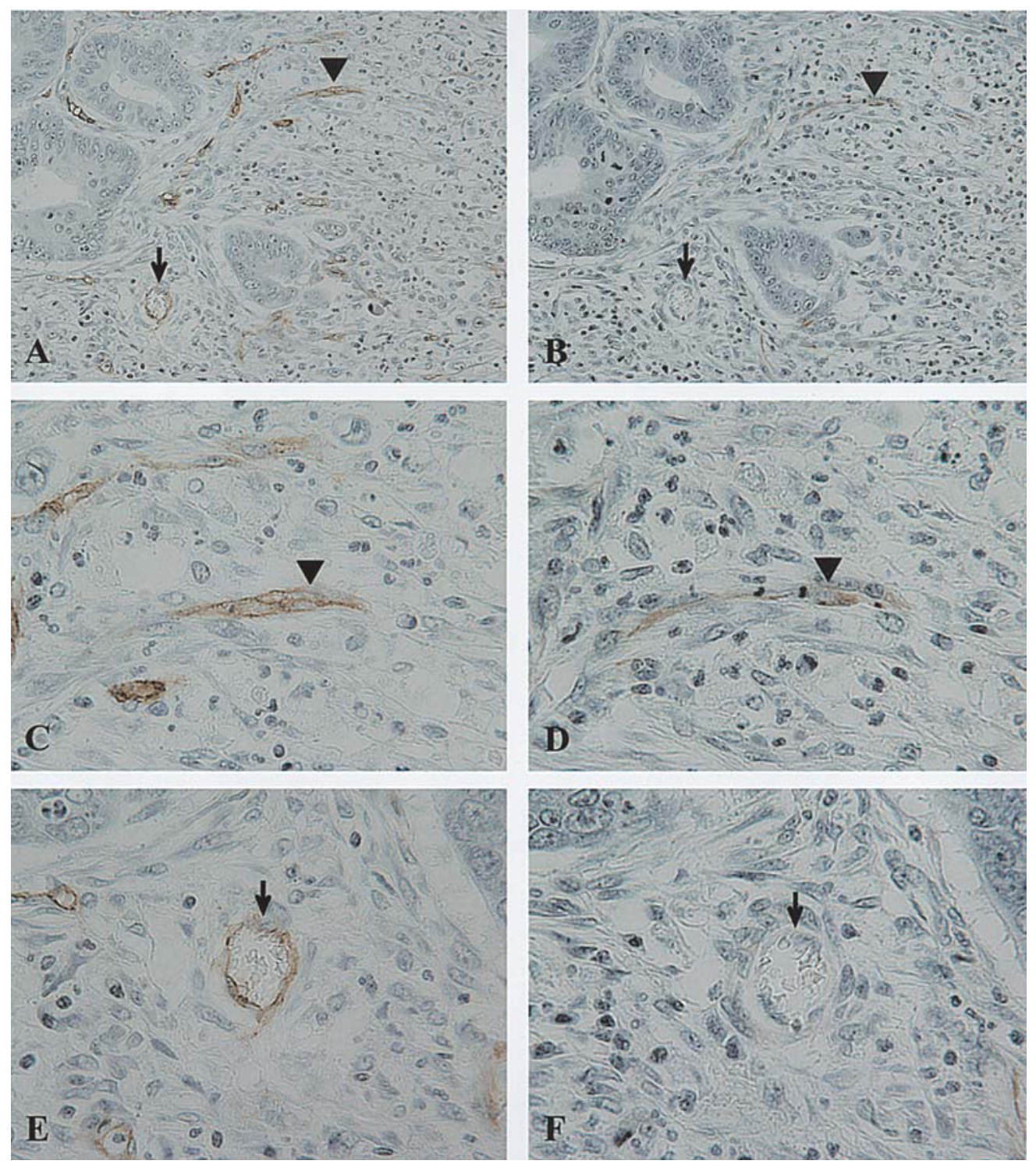

Figure 3. Immunohistochemistry of CD34 and nestin in human colorectal cancer tissue. CD34 and nestin immunoreactivities were detected in vascular endothelial cells adjacent to cancer cells, but not in colorectal cancer cells (A and B, respectively). In vascular endothelial cells of small vessels, CD34 and nestin were colocalized ( $\mathrm{C}$ and $\mathrm{D}$, arrowheads, respectively). CD34 was detected in endothelial cells of large blood vessels, but not nestin (E and F, arrows, respectively). CD34 (A, C and E) and nestin (B, D and F). Original magnification: A and B, x400; and C-F, x1000.

A p value of $<0.05$ was considered significant. Computations were performed using the StatView J version 4.5 (SAS Institute, Inc., Cary, NC, USA) software package.

\section{Results}

Identification of blood vessels with Fluospheres, CD34 and nestin in implanted colorectal tumor in nude mice. Fluospheres were detected in blood vessels of various sizes in the colorectal cancer implanted in subcutaneous tissues of nude mice by fluorescence microscopy (Fig. 1A and B). CD34 and nestin were colocalized in most of the endothelial cells (Fig. 1C and E, arrowheads, respectively). In some endothelial cells, CD34 was detected, but not nestin (Fig. 1D and F arrows, respectively). Fluospheres flowed in blood vessels with a median lumen diameter of $9.97 \mu \mathrm{m}$ (mean, 12.42 \pm 9.20 ; range, 2.72-75.83, Fig. 2). CD34 was immunostained in endothelial cells of large blood vessels with a median diameter of $9.67 \mu \mathrm{m}$ (mean, 11.40 \pm 6.39 ; range, 2.72-53.47, Fig. 2), whereas nestin was detected in endothelial cells of smaller blood vessels with a median diameter of $9.06 \mu \mathrm{m}$ (mean, 10.25 \pm 4.49 ; range, 2.72-28.70, Fig. 2).

Immunohistochemistries of nestin, CD34 and PCNA expression in human colorectal cancer tissues. We examined the localization of nestin and CD34 in human colorectal cancer tissue. CD34 and nestin immunoreactivities were detected in the cytoplasm of vascular endothelial cells adjacent to cancer cells, but not in that of any colorectal cancer cells (Fig. 3A and $\mathrm{B}$, respectively). We found that endothelial cells adjacent to the infiltrating border of the tumor showed a stronger expression of nestin than CD34. CD34 and nestin were colocalized in endothelial cells of small vessels (Fig. 3C and D, respectively). CD34-positive endothelial cells of some clearly lumen-formed blood vessels showed no nestin immunoreactivity (Fig. 3E and F, respectively). 


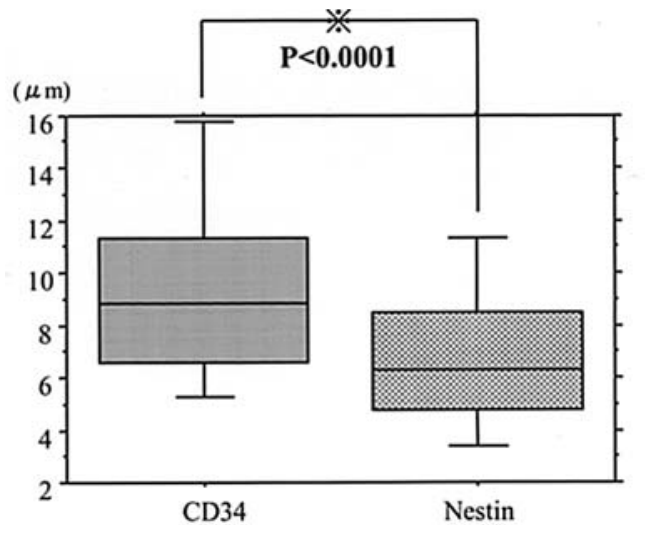

Figure 4. Diameters of CD34- and nestin-positive blood vessels in human colorectal cancer tissue. CD34 was immunostained in endothelial cells of large blood vessels with a median diameter of $8.82 \mu \mathrm{m}$ (mean, 9.77 \pm 4.52 ; range, 3.15-32.44). Nestin immunoreactivity was detected in endothelial cells of small blood vessels with a median diameter of $6.30 \mu \mathrm{m}$ (mean, $7.01 \pm 3.42$; range, 1.58-22.05). Nestin was localized in endothelial cells of smaller blood vessels than blood vessels in the case of CD34 $(\mathrm{P}<0.0001)$.

Similarly to the results of the subcutaneous tumor in nude mice, nestin immunoreactivity in human colorectal cancer tissues was detected in endothelial cells of small vessels with a median diameter of $6.30 \mu \mathrm{m}$ (mean, 7.01土3.42; range, 1.58-22.05, Fig. 4). CD34 was immunostained in endothelial cells of large blood vessels with a median diameter of $8.82 \mu \mathrm{m}$ (mean, 9.77 \pm 4.52 ; range, 3.15-32.44, Fig. 4). Nestin was identified in endothelial cells of blood vessels smaller than blood vessels in the case of CD34 ( $\mathrm{P}<0.0001$, Fig. 4).

PCNA immunoreactivity was detected in the nuclei of most colorectal cancer cells and some vascular endothelial cells (Fig. 5B arrows). In the serial sections with PCNA and nestin or CD34, more PCNA-positive cells were detected in nestin-positive endothelial cells (Fig. 5A and B) than in CD34positive endothelial cells (Fig. 5C and D). Statistically, the number ratio of PCNA-positive endothelial cells correlated with that of nestin-positive endothelial cells $(\mathrm{P}=0.002$, Table II). However, there was no relationship between the number ratio of CD34-positive endothelial cells and that of PCNA-positive endothelial cells $(\mathrm{P}=0.525$, Table II).

In situ hybridization of nestin mRNA in endothelial cells. Immunohistochemistry showed nestin expression in vascular endothelial cells of small blood vessels. Next, we examined whether nestin is synthesized in vascular endothelial cells by in situ hybridization. Nestin mRNA was clearly detected in vascular endothelial cells of small blood vessels, but not in those of large blood vessels (Fig. 6A arrows and B arrowheads, respectively). In situ hybridization using a sense probe revealed no positive signals (Fig. 6C arrows and D arrowheads).

Correlations between clinicopathological findings and nestin- or CD34-positive endothelial cells. MVDs determined by nestin ranged from 1.6 to 92.4 , with a median of 21.7 (mean, 27.20 \pm 18.64 , Table III) and MVDs determined by CD34 ranged from 1.0 to 153.0 , with a median of 59.1 (mean, 60.77 \pm 30.86 , Table IV). We examined the correlations between nestin- or CD34-positive endothelial cells and
Table II. Counts of nestin-, CD34- and PCNA-labelled cells in vessels.

\begin{tabular}{lccc}
\hline & \multicolumn{3}{c}{ PCNA } \\
\cline { 2 - 4 } Antibody & Positive & Negative \\
\hline Nestin & & $\mathrm{p}=0.002$ & \\
Positive & 67 & & 10 \\
Negative & 15 & $\mathrm{p}=0.525$ & \\
CD34 & & & 46 \\
Positive & 73 & & 0 \\
Negative & 2 & & \\
\hline
\end{tabular}

clinicopathological findings. There were no statistical differences between nestin- or CD34-positive endothelial cells and clinicopathological findings (Tables III and IV, respectively).

Disease-free survival curves. Patients with tumors characterized by MVD $<21.7$ had a better chance of survival than patients with tumors characterized by MVD $>21.7$ as determined by nestin labeling (log-rank, $\mathrm{p}=0.071$, Fig. 7A). In patients with tumors characterized by MVD $<59.1$ or $>59.1$, there was no significant difference in survival rate as determined by CD34 labeling (log-rank, p=0.135, Fig. 7B).

\section{Discussion}

CD31, CD34 and the factor VIII-related antigen are commonly used as endothelial cell markers in tumor vessels (11-13). Antibodies against these markers detect vascular endothelial cells in tumors, but the anti-factor VIII antibody does not stain endothelial cells of small blood vessels well compared with anti-CD31 or CD34 antibodies (38). CD31 occasionally labels inflammatory cells, but inflammatory infiltration camouflages endothelial cells in only a few cases (1). CD34 rarely labels collagen fibers; however, it is believed to be the most sensitive marker of newly formed endothelial cells (39). CD34 labeling has been interpreted as showing newly formed vessels in endothelial cells during tumor angiogenesis. In lung cancer tissues, the anti-CD34 antibody shows the best labeling sensitivity and specificity for vascular endothelial cells $(40,41)$. These findings suggest that CD34 is the most useful marker of angiogenesis in tumors.

Nestin has recently received attention as a marker for detecting endothelial cells of newly formed microvessels (28). In fetal tissues, nestin is strongly expressed in endothelial cells during vasculogenesis. Thereafter, nestin expression is downregulated in the vasculature of postnatal and adult animals (42). In adult tissue, nestin expression may be restricted to newly formed endothelial cells generated during angiogenesis.

Nestin- or CD34-positive endothelial cells were detected adjacent to the Fluospheres in tumor tissues of the nude mice. The diameter of nestin-positive vessels was smaller than that of CD34-positive vessels. Moreover, immunohistochemistry using colorectal tumors showed that the diameter of nestin- 
Table III. Clinical outcomes according to clinicopathologic factors and MVD determined by nestin.

\begin{tabular}{|c|c|c|c|}
\hline \multirow[t]{2}{*}{ Variable } & \multicolumn{3}{|c|}{ 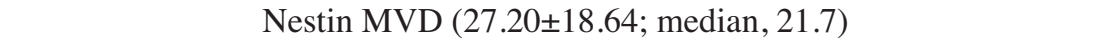 } \\
\hline & MVD<21.7 (n=51) & & MVD $>21.7(n=50)$ \\
\hline Sex & & $\mathrm{p}=0.838$ & \\
\hline Male & 31 & & 32 \\
\hline Female & 20 & & 18 \\
\hline $\begin{array}{l}\text { Mean age } \pm \text { SD } \\
\text { (range) }\end{array}$ & $\begin{array}{c}65.78 \pm 11.70 \\
(27-91)\end{array}$ & $\mathrm{p}=0.831$ & $\begin{array}{c}65.10 \pm 10.20 \\
(41-85)\end{array}$ \\
\hline Histology & & $\mathrm{p}=0.715$ & \\
\hline Well/moderate & 48 & & 46 \\
\hline Poor/mucinous & 3 & & 4 \\
\hline Location & & $\mathrm{p}=0.216$ & \\
\hline Colon & 36 & & 29 \\
\hline Rectum & 15 & & 21 \\
\hline Depth of tumor invasion & & $\mathrm{p}=0.437$ & \\
\hline $\mathrm{m}-\mathrm{sm}$ & 7 & & 10 \\
\hline mp-si & 44 & & 40 \\
\hline p-stage & & $\mathrm{p}=0.108$ & \\
\hline $0-\mathrm{II}$ & 25 & & 33 \\
\hline III-IV & 26 & & 17 \\
\hline Lymphatic invasion & & $\mathrm{p}=0.286$ & \\
\hline Positive & 38 & & 32 \\
\hline Negative & 13 & & 18 \\
\hline Vascular invasion & & $\mathrm{p}=0.429$ & \\
\hline Positive & 28 & & 23 \\
\hline Negative & 23 & & 27 \\
\hline Lymph node metastasis & & $\mathrm{p}=0.535$ & \\
\hline Positive & 20 & & 16 \\
\hline Negative & 31 & & 34 \\
\hline
\end{tabular}

positive blood vessels was smaller than that of CD34-positive vessels. These results suggest that nestin is localized in small blood vessels in colorectal tumors.

Next, to examine whether nestin-positive endothelial cells are proliferating cells, we determined the number ratio of PCNA-positive cells to nestin-positive endothelial cells. Ki-67 and PCNA are commonly used as proliferating cell markers. $\mathrm{Ki}-67$ is found in the nucleus throughout the cell cycles (G1, $\mathrm{S}, \mathrm{G} 2, \mathrm{M}$ phases) but is absent in resting (G0) cells (43). The diagnostic and prognostic values of Ki-67 immunostaining in human tumors have been widely documented and accepted (44). PCNA is a nuclear protein that has been identified as the auxiliary protein of DNA polymerase $\delta(45)$. PCNA is a marker of cells in the G1, S, G2, and M phases of the cell cycle (43). Its gene expression correlates with cell proliferation. We examined the cell proliferative features of endothelial cells in colorectal cancer tissue using these two proliferation markers. PCNA-positive nuclei were distributed in numerous endothelial cells, and few Ki-67-positive cells existed in endothelial cells of colorectal cancer tissue. Ki-67 disappears immediately after cell replication, whereas PCNA proteins remain longer than Ki-67 in the nucleus of cells (43). Nestin is considered to have a similar expression pattern to PCNA in the nucleus of vascular endothelial cells. Nestin induces the disassembly of vimentin to nonfilamentous aggregates or particles in mitotic cells for an equal distribution of vimentin in daughter cells (28). Thus, we employed PCNA as a cell proliferation marker of endothelial cells in colorectal cancer tissues and found that nestin-positivity correlates with PCNApositivity in the cells. This result shows that nestin expression correlates with endothelial cell proliferation.

In situ hybridization revealed that nestin mRNA is detected in endothelial cells of blood vessels of human colorectal cancer tissues. Nestin is synthesized by vascular endothelial cells in cancer tissues. These lines of evidence suggest that nestin is a novel angiogenesis marker in colorectal cancer.

MVD was suggested to be closely related to hematogenous metastasis to distant organs from the primary site, and to influence survival (3). MVD is thus considered to be an independent and important prognostic indicator in invasive 

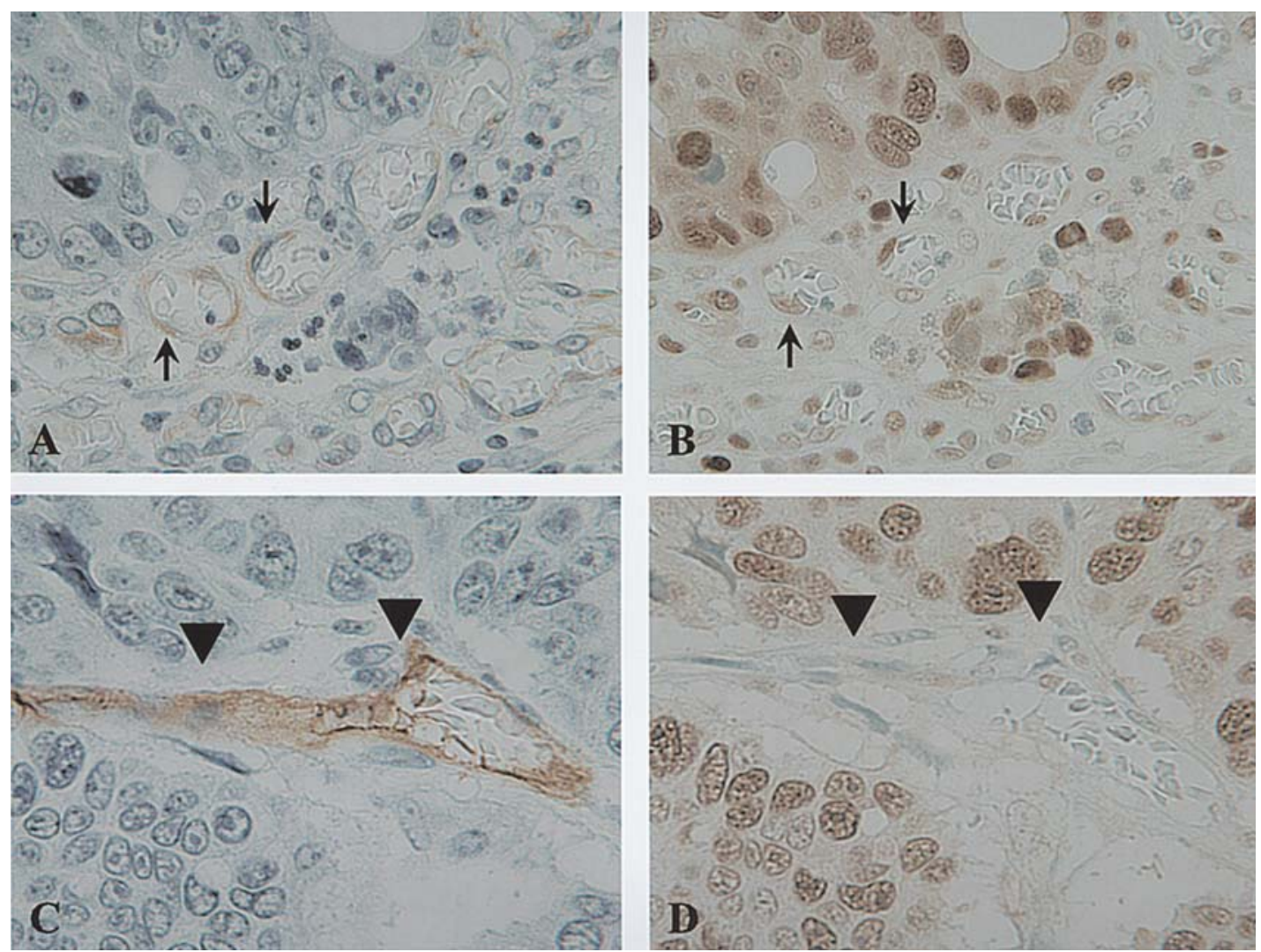

Figure 5. Immunohistochemistry of nestin, CD34 and PCNA in colorectal cancer tissue. Nestin-positive vascular endothelial cells coexpressed a proliferating marker, PCNA, in their nucleus (A and B, arrows, respectively). On the other hand, many of the CD34-positive vascular endothelial cells did not coexpress PCNA in their nucleus (C and D, arrowheads, respectively). Nestin (A), PCNA (B and D) and CD34 (C). Original magnification: A-D, x1000.
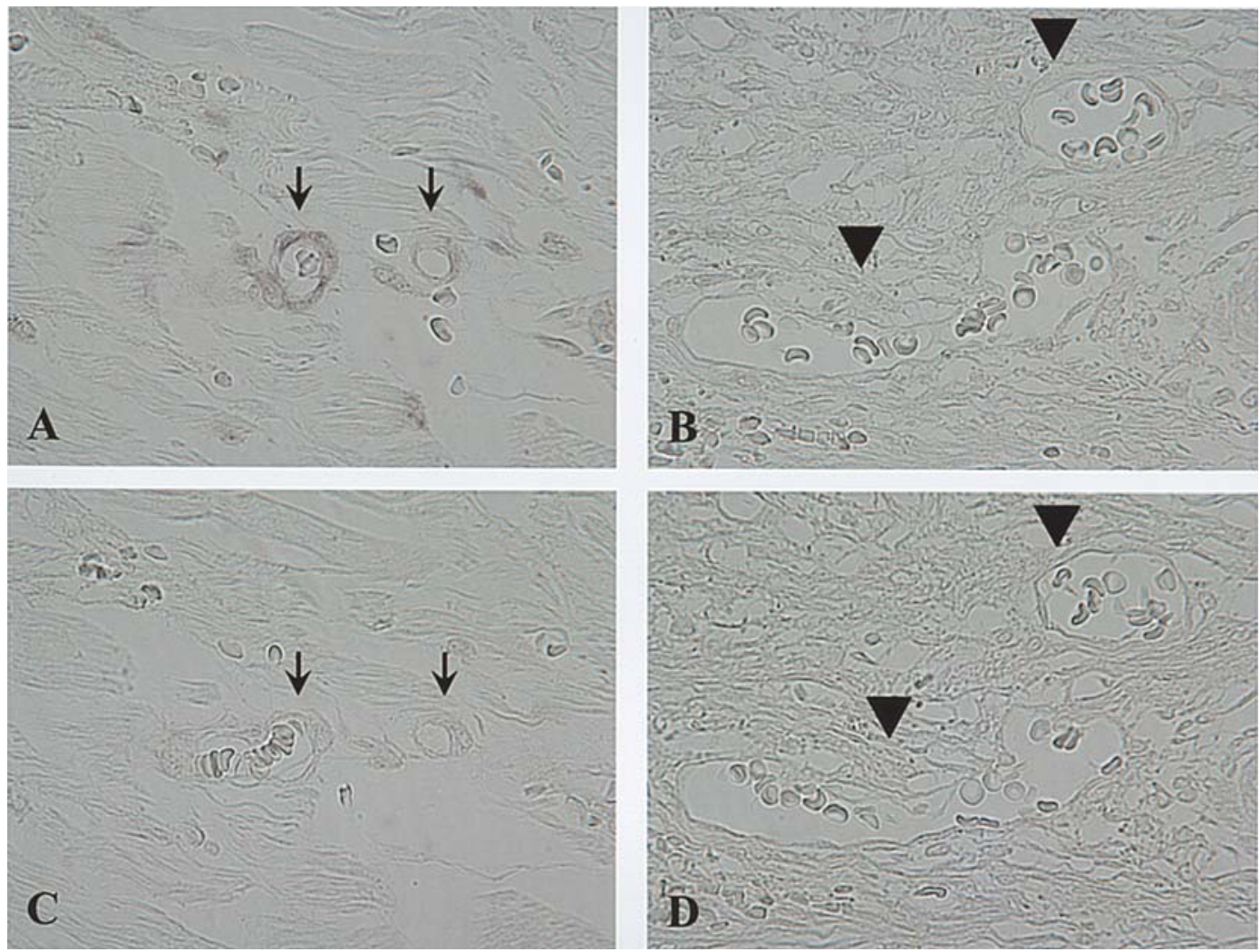

Figure 6. In situ hybridization of nestin mRNA in endothelial cells. Nestin mRNA was detected in vascular endothelial cells of small blood vessels, but not in vascular endothelial cells of large blood vessels (A arrows and B arrowheads, respectively). The sense probe did not show any positive signals in endothelial cells (C arrows and D arrowheads). Antisense (A and B) and sense (C and D). Original magnification: A-D, x1000. 
Table IV. Clinical outcomes according to clinicopathologic factors and MVD determined by CD34.

\begin{tabular}{|c|c|c|c|}
\hline \multirow[b]{2}{*}{ Variable } & \multicolumn{3}{|c|}{ CD34 MVD (60.77 $\pm 30.86 ;$ median, 59.1) } \\
\hline & MVD<59.1 (n=51) & & MVD $>59.1(n=50)$ \\
\hline Sex & & $\mathrm{p}=0.684$ & \\
\hline Male & 33 & & 30 \\
\hline Female & 18 & & 20 \\
\hline $\begin{array}{l}\text { Mean age } \pm \text { SD } \\
\text { (range) }\end{array}$ & $\begin{array}{c}65.86 \pm 12.63 \\
(27-91)\end{array}$ & $\mathrm{p}=0.991$ & $\begin{array}{c}65.02 \pm 12.63 \\
(41-85)\end{array}$ \\
\hline Histology & & $\mathrm{p}=0.436$ & \\
\hline Well/moderate & 46 & & 48 \\
\hline Poor/mucinous & 5 & & 2 \\
\hline Location & & $\mathrm{p}>0.999$ & \\
\hline Colon & 33 & & 32 \\
\hline Rectum & 18 & & 18 \\
\hline Depth of tumor invasion & & $\mathrm{p}>0.999$ & \\
\hline $\mathrm{m}-\mathrm{sm}$ & 9 & & 8 \\
\hline mp-si & 42 & & 42 \\
\hline p-stage & & $\mathrm{p}=0.229$ & \\
\hline $0-\mathrm{II}$ & 26 & & 32 \\
\hline III-IV & 25 & & 18 \\
\hline Lymphatic invasion & & $\mathrm{p}=0.831$ & \\
\hline Positive & 36 & & 34 \\
\hline Negative & 15 & & 16 \\
\hline Vascular invasion & & $\mathrm{p}=0.429$ & \\
\hline Positive & 28 & & 23 \\
\hline Negative & 23 & & 27 \\
\hline Lymph node metastasis & & $\mathrm{p}=0.535$ & \\
\hline Positive & 20 & & 16 \\
\hline Negative & 31 & & 34 \\
\hline
\end{tabular}

A

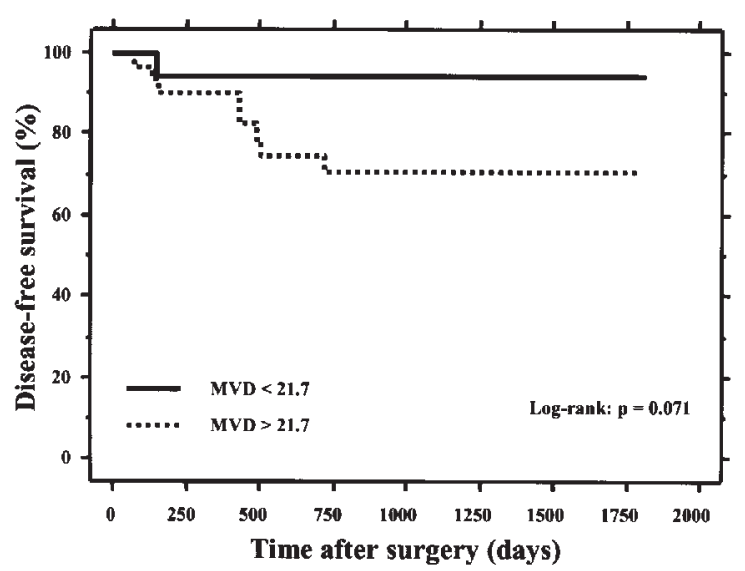

B

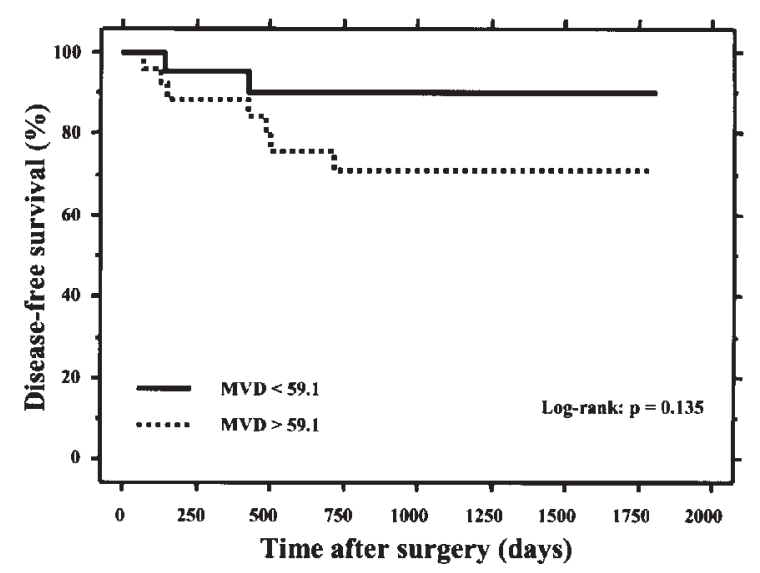

Figure 7. Disease-free survival curve based on MVD determined by nestin (A) or CD34 (B). (A) Patients with tumors characterized by MVD <21.7 had a better chance of survival than patients with tumors characterized by MVD >21.7 as determined by nestin ( $\mathrm{p}=0.071$, Kaplan-Meier method). (B) In patients with tumors characterized by MVD $<59.1$ or $>59.1$, there was no significant difference in survival rate as determined by CD34 ( $\mathrm{p}=0.135$, Kaplan-Meier method). 
breast carcinoma, lung cancer, and colorectal cancer $(1,14,46)$. In colorectal cancer, MVD estimated by immunohistochemical staining correlates with hematogenous metastasis (3). Our study showed that the MVDs of nestin-positive and CD34positive blood vessels are not related to clinicopathological factors. However, nestin is related to prognosis better than CD34. This suggests that the MVD of nestin-positive blood vessels correlates with the recurrence and metastasis of colorectal cancer.

In conclusion, the measurement of the MVD of blood vessels immunostained by nestin is a useful technique for detecting newly proliferating endothelial cells in colorectal angiogenesis. The MVD of nestin-positive blood vessels may be a novel marker of neovasculature and a target of antiangiogenic therapy for colorectal cancer patients.

\section{Acknowledgements}

We express our appreciation to Mr. Takenori Fujii, Ms. Yoko Kawamoto, Mr. Kiyoshi Teduka, Ms. Kiyoko Kawahara and Ms. Taeko Suzuki (Department of Integrative Pathology, Nippon Medical School) for their technical assistance.

\section{References}

1. Hansen S, Grabau DA, Rose C, Bak M and Sorensen FB: Angiogenesis in breast cancer: a comparative study of the observer variability of methods for determining microvessel density. Lab Invest 78: 1563-1573, 1998.

2. Schoell WM, Pieber D, Reich O, et al: Tumor angiogenesis as a prognostic factor in ovarian carcinoma: quantification of endothelial immunoreactivity by image analysis. Cancer 80 : 2257-2262, 1997.

3. Tomisaki S, Ohno S, Ichiyoshi Y, Kuwano H, Maehara Y and Sugimachi K: Microvessel quantification and its possible relation with liver metastasis in colorectal cancer. Cancer 77: 1722-1728, 1996.

4. Liotta LA, Saidel MG and Kleinerman J: The significance of hematogenous tumor cell clumps in the metastatic process. Cancer Res 36: 889-894, 1976.

5. Srivastava A, Laidler P, Hughes LE, Woodcock J and Shedden EJ: Neovascularization in human cutaneous melanoma: a quantitative morphological and Doppler ultrasound study. Eur J Cancer Clin Oncol 22: 1205-1209, 1986.

6. Macchiarini P, Fontanini G, Hardin MJ, Squartini F and Angeletti CA: Relation of neovascularisation to metastasis of non-small-cell lung cancer. Lancet 340: 145-146, 1992.

7. Wakui S, Furusato M, Itoh T, et al: Tumour angiogenesis in prostatic carcinoma with and without bone marrow metastasis: a morphometric study. J Pathol 168: 257-262, 1992.

8. Tanigawa N, Matsumura M, Amaya $\mathrm{H}$, et al: Tumor vascularity correlates with the prognosis of patients with esophageal squamous cell carcinoma. Cancer 79: 220-225, 1997.

9. Tanigawa N, Amaya H, Matsumura M and Shimomatsuya T: Association of tumour vasculature with tumour progression and overall survival of patients with non-early gastric carcinomas. Br J Cancer 75: 566-571, 1997.

10. Takahashi Y, Tucker SL, Kitadai Y, et al: Vessel counts and expression of vascular endothelial growth factor as prognostic factors in node-negative colon cancer. Arch Surg 132: 541-546, 1997.

11. Uzzan B, Nicolas P, Cucherat M and Perret GY: Microvessel density as a prognostic factor in women with breast cancer: a systematic review of the literature and meta-analysis. Cancer Res 64: 2941-2955, 2004.

12. Vieira SC, Zeferino LC, Da Silva BB, et al: Quantification of angiogenesis in cervical cancer: a comparison among three endothelial cell markers. Gynecol Oncol 93: 121-124, 2004.

13. Tomoda M, Maehara Y, Kakeji Y, Ohno S, Ichiyoshi Y and Sugimachi K: Intratumoral neovascularization and growth pattern in early gastric carcinoma. Cancer 85: 2340-2346, 1999.
14. Meert AP, Paesmans M, Martin B, et al: The role of microvessel density on the survival of patients with lung cancer: a systematic review of the literature with meta-analysis. Br J Cancer 87: 694-701, 2002.

15. Lendahl U, Zimmerman LB and McKay RD: CNS stem cells express a new class of intermediate filament protein. Cell 60: 585-595, 1990.

16. Marvin MJ, Dahlstrand J, Lendahl U and McKay RD: A rod end deletion in the intermediate filament protein nestin alters its subcellular localization in neuroepithelial cells of transgenic mice. J Cell Sci 111: 1951-1961, 1998.

17. Almazan G, Vela JM, Molina-Holgado E and Guaza C: Reevaluation of nestin as a marker of oligodendrocyte lineage cells. Microsc Res Tech 52: 753-765, 2001.

18. Frojdman K, Pelliniemi LJ, Lendahl U, Virtanen I and Eriksson JE: The intermediate filament protein nestin occurs transiently in differentiating testis of rat and mouse. Differentiation 61: 243-249, 1997.

19. Amoh Y, Li L, Yang M, et al: Nascent blood vessels in the skin arise from nestin-expressing hair-follicle cells. Proc Natl Acad Sci USA 101: 13291-13295, 2004.

20. Lardon J, Rooman I and Bouwens L: Nestin expression in pancreatic stellate cells and angiogenic endothelial cells. Histochem Cell Biol 117: 535-540, 2002.

21. Ehrmann J, Kolar Z and Mokry J: Nestin as a diagnostic and prognostic marker: immunohistochemical analysis of its expression in different tumours. J Clin Pathol 58: 222-223, 2005.

22. Klein T, Ling Z, Heimberg H, Madsen OD, Heller RS and Serup P: Nestin is expressed in vascular endothelial cells in the adult human pancreas. J Histochem Cytochem 51: 697-706, 2003.

23. Terling C, Rass A, Mitsiadis TA, Fried K, Lendahl U and Wroblewski J: Expression of the intermediate filament nestin during rodent tooth development. Int J Dev Biol 39: 947-956, 1995 .

24. Sejersen T and Lendahl U: Transient expression of the intermediate filament nestin during skeletal muscle development. J Cell Sci 106: 1291-1300, 1993.

25. Quaini F, Urbanek K, Beltrami AP, et al: Chimerism of the transplanted heart. N Engl J Med 346: 5-15, 2002.

26. El-Helou V, Dupuis J, Proulx C, et al: Resident nestin+ neurallike cells and fibers are detected in normal and damaged rat myocardium. Hypertension 46: 1219-1300, 2005.

27. Sugawara K, Kurihara H, Negishi M, et al: Nestin as a marker for proliferative endothelium in gliomas. Lab Invest 82: 345-351, 2002.

28. Mokry J, Cizkova D, Filip S, et al: Nestin expression by newly formed human blood vessels. Stem Cells Dev 13: 658-664, 2004.

29. Ishiwata T, Kudo M, Onda M, et al: Defined localization of nestin-expressing cells in L-arginine-induced acute pancreatitis. Pancreas 32: 360-368, 2006.

30. Kim HS, Kang HS, Messam CA, Min KW and Park CS: Comparative evaluation of angiogenesis in gastric adenocarcinoma by nestin and CD34. Appl Immunohistochem Mol Morphol 10: 121-127, 2002.

31. Jasper MS, McDermott P, Gann DS and Engeland WC: Measurement of blood flow to the adrenal capsule, cortex and medulla in dogs after hemorrhage by fluorescent microspheres. J Auton Nerv Syst 30: 159-167, 1990.

32. Rovainen CM, Woolsey TA, Blocher NC, Wang DB and Robinson OF: Blood flow in single surface arterioles and venules on the mouse somatosensory cortex measured with videomicroscopy, fluorescent dextrans, nonoccluding fluorescent beads, and computer-assisted image analysis. J Cereb Blood Flow Metab 13: 359-371, 1993.

33. Kowallik P, Schulz R, Guth BD, et al: Measurement of regional myocardial blood flow with multiple colored microspheres. Circulation 83: 974-982, 1991.

34. Springer ML, Ip TK and Blau HM: Angiogenesis monitored by perfusion with a space-filling microbead suspension. Mol Ther 1: 82-87, 2000.

35. Tibbetts LM, Chu MY, Hager JC, Dexter DL and Calabresi P: Chemotherapy of cell-line-derived human colon carcinomas in mice immunosuppressed with antithymocyte serum. Cancer 40: 2651-2659, 1977.

36. Lu YP, Ishiwata T, Kawahara K, et al: Expression of lumican in human colorectal cancer cells. Pathol Int 52: 519-526, 2002.

37. Vermeulen PB, Gasparini G, Fox SB, et al: Quantification of angiogenesis in solid human tumours: an international consensus on the methodology and criteria of evaluation. Eur J Cancer 32A: 2474-2484, 1996. 
38. Tanigawa N, Amaya H, Matsumura M, et al: Extent of tumor vascularization correlates with prognosis and hematogenous metastasis in gastric carcinomas. Cancer Res 56: 2671-2676, 1996.

39. Sauter B, Foedinger D, Sterniczky B, Wolff K and Rappersberger K: Immunoelectron microscopic characterization of human dermal lymphatic microvascular endothelial cells. Differential expression of CD31, CD34, and type IV collagen with lymphatic endothelial cells vs blood capillary endothelial cells in normal human skin, lymphangioma, and hemangioma in situ. J Histochem Cytochem 46: 165-176, 1998

40. Yano T, Tanikawa S, Fujie T, Masutani M and Horie T: Vascular endothelial growth factor expression and neovascularisation in non-small cell lung cancer. Eur J Cancer 36: 601-609, 2000.

41. Offersen BV, Pfeiffer P, Hamilton-Dutoit S and Overgaard J: Patterns of angiogenesis in nonsmall-cell lung carcinoma. Cancer 91: 1500-1509, 2001.
42. Krum JM and Rosenstein JM: Transient coexpression of nestin, GFAP, and vascular endothelial growth factor in mature reactive astroglia following neural grafting or brain wounds. Exp Neurol 160: 348-360, 1999

43. Iwata K, Nakagawa $\mathrm{H}$ and Hashizume Y: Significance of MIB-1, PCNA indices, and p53 protein over-expression in intramedullary tumors of the spinal cord. Noshuyo Byori 13: 73-78, 1996.

44. Scott RJ, Hall PA, Haldane JS, et al: A comparison of immunohistochemical markers of cell proliferation with experimentally determined growth fraction. J Pathol 165: 173-178, 1991.

45. Robbins BA, de la Vega D, Ogata K, Tan EM and Nakamura RM: Immunohistochemical detection of proliferating cell nuclear antigen in solid human malignancies. Arch Pathol Lab Med 111: 841-845, 1987

46. Fox SH, Whalen GF, Sanders MM, et al: Angiogenesis in normal tissue adjacent to colon cancer. J Surg Oncol 69: 230-234, 1998. 